\title{
Dementia (Including Alzheimer's Disease) can be Prevented: Statement Supported by International Experts
}

On the occasion of the G8 dementia summit in London on 11 December 2013, we call upon the governments of the G8 countries to make prevention of dementia one of their major health aims.

- The commonest dementia (Alzheimer's disease) is irreversible and develops slowly over many years.

- So far drugs have only relieved symptoms, but have not been effective against disease progression.

- About half of the large decline in deaths from heart disease and stroke over the past 50 years has been the result of public health measures to modify risk factors. We are confident that the same approach will work for dementia.

- We propose that a concerted effort be made to discover modifiable risk factors for dementia and to exploit those already identified.

- International collaboration is needed on largescale clinical trials to test whether modifying risk factors will lead to prevention of dementia.

- Health authorities should aim to identify high risk individuals at an early stage, when intervention is more likely to help.

- There is already sufficient evidence to justify immediate action. Trials in those at risk of developing dementia should be done of the following: exercise; controlling blood sugar, including diabetes treatment; depression treatment; high blood pressure treatment; B vitamins; omega-3 fatty acids; cognitive training; and social activities.

- Public health policies should encourage middleaged people to stop smoking; exercise; eat diets rich in fruit and vegetables and fish (Mediterranean foods); avoid becoming obese and diabetic; avoid excessive alcohol intake; treat high blood pressure. In other words - tell people that adopting a healthy lifestyle may help to ward off dementia as it does for other diseases.

- It is notable that the prevalence of dementia and cognitive impairment in some Western countries is now less than anticipated, possibly as a result of changes in lifestyle and the reduction in cardiovascular risk factors, although this may not necessarily mean that worldwide trends in the burden of dementia will be substantially reduced.

- We estimate that about half of Alzheimer's disease cases worldwide might be attributable to known risk factors. Taking immediate action on the known risk factors could perhaps prevent up to one-fifth of predicted new cases by 2025 .

- The worldwide costs of dementia in 2010 have been estimated to be $\$ 604$ billion, most of it in G8 countries. Prevention of dementia would thus not only prevent a lot of human suffering but would save huge sums of money.

- We call upon the Health Ministers of the G8 countries to greatly increase government funding for research on the prevention of dementia.

A. David Smith, Department of Pharmacology, University of Oxford, Oxford, UK; david.smith @ pharm.ox.ac.uk

Kristine Yaffe, University of California, San Francisco, San Francisco, CA, USA; Kristine.Yaffe @ucsf.edu

The following 109 scientists from 36 countries have signed in support:

P Aisen (University of California, San Diego)

M Albert (Johns Hopkins University, Baltimore, MD) K Anstey (Australian National University, Canberra) 
J Avila (Centro de Biologia Molecular Severo Ochoa, Madrid)

S Banerjee (University of Sussex, Brighton)

DE Barnes (University of California, San Francisco)

MS Beeri (Mount Sinai School of Medicine,

New York)

DA Bennett (Rush University Medical Center, Chicago)

S Black (University of Toronto)

C Brayne (University of Cambridge)

J Breitner (McGill University, Montreal)

M Breteler (German Center for Neurodegenerative Diseases, Bonn)

H Brodaty (University of New South Wales, Sydney)

C Chen (National University of Singapore)

MJ Chiu (President Taiwan Alzheimer's Association,

National Taiwan University, Taipei)

M Combrinck (University of Cape Town)

CW Cotman (University of California, Irvine)

P Davies (Feinstein Institute, New York)

C deCarli (University of California Davis, Sacramento)

IV Damulin (I.M. Sechenov First Moscow State

Medical University, Moscow)

P Dal-Bianco (Medical University of Vienna)

$\mathrm{J}$ de la Torre (University of Texas, Austin)

A de Silva (University of Kelaniya, Colombo, Sri Lanka)

B De Strooper (Catholic University of Leuven)

B Dubois (University of Paris VI)

K Engedal (University of Oslo)

S Engelborghs (University of Antwerp)

MM Esiri (University of Oxford)

RM Faull (University of Auckland)

AM Fjell (University of Oslo)

L Flicker (University of Western Australia, Perth)

A Flöel (Charité-Universitätsmedizin, Berlin)

O Forlenza (University of Sao Paulo, Brazil)

L Fratiglioni (Karolinska Institute, Stockholm)

GB Frisoni (University of Geneva and IRCCS

Fatebenefratelli, Brescia)

S Gauthier (McGill University, Montreal)

S.I. Gavrilova (Mental Health Research Center RAMS, Moscow)

H Hampel (Pierre and Marie Curie University, Paris)

$\mathrm{H}$ Hendrie (Indiana University, Indianapolis)

T Iwatsubo (University of Tokyo)

R Jacoby (University of Oxford)

J Jia (Beijing Capital Medical University)

KA Jellinger (Medical University of Vienna)

RN Kalaria (University of Newcastle, UK)

ZS Khachaturian (The Campaign to Prevent

Alzheimer's Disease by 2020, Potomac, MD)
M Kivipelto (Karolinska Institute, Stockholm)

D Knopman (Mayo Clinic, Rochester, MN)

T Kwok (Chinese University, Hong Kong)

K Langa (University of Michigan, Ann Arbor)

EB Larson (University of Washington, Seattle)

L Launer (National Institute on Aging, Bethesda, MD)

N Lautenschlager (University of Melbourne)

BA Lawlor (Trinity College, Dublin)

J Lindesay (University of Leicester, UK)

A Lobo (University of Zaragoza, Spain)

J Lökk (Karolinska Institute, Stockholm)

O Makeeva (Russian Academy of Medical Sciences, Tomsk)

J Marksteiner (President, Austrian Alzheimer Society)

A McCaddon (Cardiff University Medical School)

K Meguro (Tohoku University, Sendai, Japan)

LT Middleton (Imperial College, London)

MC Morris (Rush University, Chicago)

DL Na (Sungkyunkwan University School of Medicine, Seoul)

MWS Nasrun (Indonesian Alzheimer Association, Universitas Indonesia, Jakarta)

A Ogunniyi (University College Hospital, Ibadan, Nigeria

S Pendelbury (Oxford NIHR Biomedical Research Centre)

G Perry (University of Texas, San Antonio)

RC Petersen (Mayo Clinic, Rochester, MN)

VP Puzyrev (Institute of Medical Genetics, SB RAMS, Tomsk, Russia)

G Rebok (Johns Hopkins University, Baltimore, MD)

G Rees (CEO, Alzheimer's Australia)

H Refsum (University of Oslo)

E Reynolds (King's College, London)

E Richard (University of Amsterdam)

J Rinne (University of Turku, Finland)

K Ritchie (INSERM, Montpellier)

WA Rocca (Mayo Clinic, Rochester, MN)

IH Rosenberg (Tufts University, Boston)

PS Sachdev (University of New South Wales)

N Scarmeas (Columbia University New York and University of Athens)

S Scarpa (University of Rome La Sapienza)

R Schmidt (Medical University, Graz, Austria)

P Scheltens (VU University Medical Center, Amsterdam)

S Seshadri (Boston University)

A Singh-Manoux (INSERM, Villejuif)

I Skoog (University of Gothenburg)

T Sobow (Medical University of Lodz, Poland)

R Sperling (Harvard University, Boston) 
P Srisuwan (Phramongkutklao Hospital and College of Medicine, Bangkok)

R Stewart (Institute of Psychiatry, London)

DY Suharya (Executive Director, Alzheimer's Indonesia)

M Tripathi (All India Institute of Medical Sciences, New Delhi)

AM Troen (Hebrew University of Jerusalem, Israel)

J Trojanowski (University of Pennsylvania, Philadelphia)

SJ van Rensburg (University of Stellenbosch, South Africa)

B Vellas (University of Toulouse)

G Waldemar (Director, Danish Dementia Research Centre, University of Copenhagen)

$\mathrm{H}$ Wang (Peking University Institute of Mental Health)

JZ Wang (Tongji Medical College, HUST, Wuhan, P.R. China)

M Weiner (University of California, San Francisco)

LJ Whalley (University Aberdeen, Scotland)

LR White (Honolulu-Asia Aging Study, Chaminade University, Hawaii)

PJ Whitehouse (Case Western Reserve University, Cleveland, $\mathrm{OH})$

R Whitmer (Kaiser Permanente, Oakland, California)

A Wimo (Karolinska Institute, Stockholm)

R Wurtman (MIT, Cambridge, Mass)

S-Y Yoon (University of Ulsan College of Medicine, Seoul)

VV Zakharov (I.M. Sechenov First Moscow State Medical University, Moscow)

NG Zhukova (Siberian State Medical University, Tomsk)

IA Zhukova (Siberian State Medical University, Tomsk)

Some selected references to recent relevant literature are:

Designing prevention programmes to reduce incidence of dementia: Prospective cohort study of modifiable risk factors.

Ritchie, K., I. Carriere, C. W. Ritchie, C. Berr, S. Artero and M. L. Ancelin. Bmj (2010) 341: c3885.

The projected effect of risk factor reduction on Alzheimer's disease prevalence.

Barnes, D. E. and K. Yaffe. Lancet Neurol (2011) 10:819-828.

Creating a transatlantic research enterprise for preventing Alzheimer's disease.
Khachaturian, Z. S., et al. Alzheimers Dement (2009) 5:361-366.

Prevent Alzheimer's disease by 2020: A national strategic goal.

Khachaturian, Z. S. and A. S. Khachaturian. Alzheimers Dement (2009) 5:81-84.

Developing a global strategy to prevent Alzheimer's disease: Leon Thal Symposium 2010.

Khachaturian, Z. S., et al. Alzheimers Dement (2011) 7:127-132.

Efficacy of Souvenaid in mild Alzheimer's disease: Results from a randomized, controlled trial.

Scheltens, P., et al. J Alzheimers Dis (2012) 31:225-236.

Mediterranean diet, cognitive function, and dementia: A systematic review.

Lourida, I., M. Soni, J. Thompson-Coon, N. Purandare, I. A. Lang, O. C. Ukoumunne and D. J. Llewellyn. Epidemiology (2013) 24:479-489.

Can we prevent Alzheimer's disease? Secondary "prevention" trials in Alzheimer's disease.

Carrillo, M. C., H. R. Brashear, V. Logovinsky, J. M. Ryan, H. H. Feldman, E. R. Siemers, S. Abushakra, D. M. Hartley, R. C. Petersen, A. S. Khachaturian and R. A. Sperling. Alzheimer's Dementia (2013) 9:123-131.e121.

Midlife risk score for the prediction of dementia four decades later.

Exalto, L. G., C. P. Quesenberry, D. Barnes, M. Kivipelto, G. J. Biessels and R. A. Whitmer. Alzheimers Dement (2013), doi: 10.1016/j.jalz.2013. 05.1772

Long-chain omega-3 fatty acids improve brain function and structure in older adults.

Witte, A. V., L. Kerti, H. M. Hermannstadter, J. B. Fiebach, S. J. Schreiber, J. P. Schuchardt, A. Hahn and A. Floel. Cereb Cortex (2013), doi: 10.1093/cercor/bht 163 .

Preventing Alzheimer's disease-related gray matter atrophy by B-vitamin treatment.

Douaud, G., H. Refsum, C. A. de Jager, R. Jacoby, T. E. Nichols, S. M. Smith and A. D. Smith. Proc Natl Acad Sci U S A (2013) 110:95239528. 
Nonpharmacologic treatment and prevention strategies for dementia.

Yaffe, K. and T. Hoang. Continuum (Minneap Minn) (2013) 19:372-381.

Trends in the prevalence and mortality of cognitive impairment in the United States: is there evidence of a compression of cognitive morbidity?

Langa, K. M., E. B. Larson, J. H. Karlawish, D. M. Cutler, M. U. Kabeto, S. Y. Kim and A. B. Rosen. Alzheimers Dement (2008) 4:134-144.

The effect of dementia trends and treatments on longevity and disability: A simulation model based on the MRC Cognitive Function and Ageing Study (MRC CFAS).

Jagger, C., R. Matthews, J. Lindesay, T. Robinson, P. Croft and C. Brayne. Age Ageing (2009) 38:319-325.

Methodological challenges in designing dementia prevention trials - the European Dementia Prevention Initiative (EDPI).

Richard, E., S. Andrieu, A. Solomon, F. Mangialasche, S. Ahtiluoto, E. P. Moll van Charante, N. Coley, L. Fratiglioni, A. S. Neely, B. Vellas, W. A. van Gool and M. Kivipelto. J Neurol Sci (2012) 322:64-70.

Trends in the incidence and prevalence of Alzheimer's disease, dementia, and cognitive impairment in the United States.

Rocca, W. A., R. C. Petersen, D. Knopman, S., L. E. Hebert, D. A. Evans, K. S. Hall, S. Gao, F. W. Unverzagt, K. M. Langa, E. B. Larson and L. White, R. Alzheimers Dement (2011) 7:80-93.

Is dementia incidence declining?: Trends in dementia incidence since 1990 in the Rotterdam Study.

Schrijvers, E. M., B. F. Verhaaren, P. J. Koudstaal, A. Hofman, M. A. Ikram and M. M. Breteler. Neurology (2012) 78:1456-1463.

Twenty-year changes in dementia occurrence suggest decreasing incidence in central Stockholm, Sweden.

Qiu, C., E. von Strauss, L. Backman, B. Winblad and L. Fratiglioni. Neurology (2013) 80:18881894.

A two-decade comparison of prevalence of dementia in individuals aged 65 years and older from three geographical areas of England: Results of the Cognitive Function and Ageing Study I and II.
Matthews, F. E., A. Arthur, L. E. Barnes, J. Bond, C. Jagger, L. Robinson, C. Brayne, on behalf of the Medical Research Council Cognitive Function and Ageing Study. Lancet (2013) 382:1405-1412.

The worldwide economic impact of dementia 2010.

Wimo, A., L. Jonsson, J. Bond, M. Prince, B. Winblad. Alzheimers Dement (2013) 9:1-11 e13.

The global prevalence of dementia: A systematic review and metaanalysis.

Prince, M., R. Bryce, E. Albanese, A. Wimo, W. Ribeiro and C. P. Ferri. Alzheimers Dement (2013) 9:63-75 e62.

New insights into the dementia epidemic.

Larson, E. B., K. Yaffe and K. M. Langa. New Engl J Med (2013), doi: 10.1056/NEJMp1311405.

Some international and national initiatives

European Dementia Prevention Initiative: http:// www.edpi.org/

The Healthy Brain Initiative (CDC and Alzheimer's Association, USA): http://www.cdc. gov/aging/healthybrain/roadmap.htm

OECD Global Challenge of Alzheimer's disease: http://www.oecd-ilibrary.org/science-and-technology/ emerging-trends-in-biomedicine-and-health-technolo gy-innovation_5k44zcpt65vc-en

A National Alzheimer's Strategic Plan (Alzheimer's Association, 2009): http://www.alz.org/doc uments/national/report_asg_alzplan.pdf

National Plan to Address Alzheimer's Disease: 2013 update: http://aspe.hhs.gov/daltcp/napa/NatlPlan 2013.pdf

National dementia strategies for the UK (Alzheimer's Society): http://www.alzheimers.org. uk/ndstrategies

UK Department of Health statement (September 2013): http://dementiachallenge.dh.gov.uk/2013/0 9/25/on-the-road-to-the-g8-dementia-summit/

\section{CONFLICT OF INTEREST STATEMENT}

ADS is named as inventor on patents held by the University of Oxford for the use of B vitamins 
in the treatment of mild cognitive impairment and Alzheimer's disease; he has grant support from the Norman Collisson Foundation. KY serves on the data and safety monitoring boards for the National Institute on Aging, Takeda Pharmaceutical Company Limited and Beeson Scientific Advisory and is a consultant to Pfizer and Novartis; she has grant support from National Institute on Aging, Alzheimer's Association, American Health Assistance Foundation, the California Department of Public Health, and the US Department of Defense. 